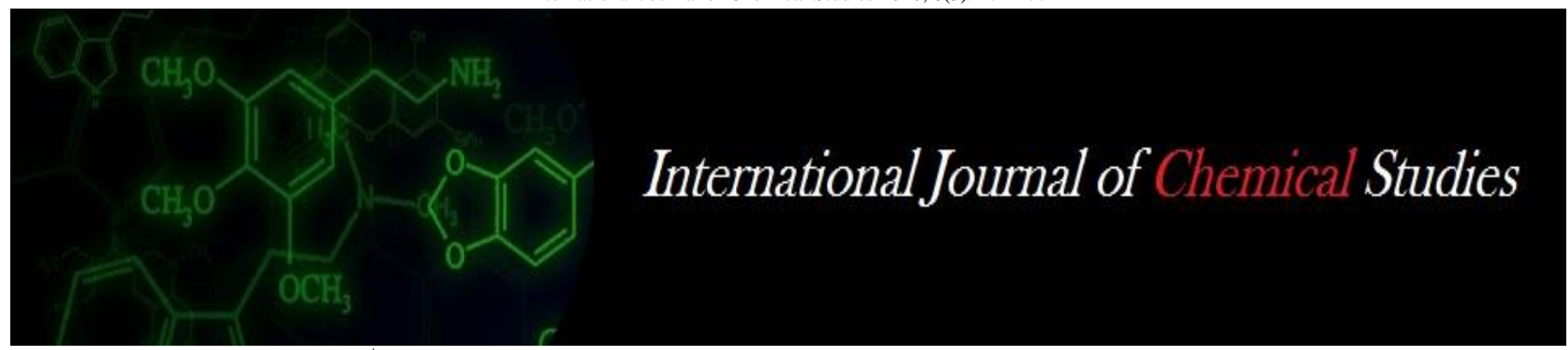

P-ISSN: 2349-8528

E-ISSN: 2321-4902

www.chemijournal.com

IJCS 2020; 8(5): 472-477

(C) 2020 IJCS

Received: 10-07-2020

Accepted: 12-08-2020

Dileepa KC

M. Tech (Food Technology)

Department of Food Processing

Technology College of

Community Science University

of Agricultural Sciences,

Dharwad, Karnataka, India

\section{Dr. Hemalatha S}

Professor and Head, Department of Food Processing Technology

College of Community Science

University of Agricultural

Sciences, Dharwad, Karnataka, India

\section{Dr. Pushpa Bharati}

Professor, Department of Food Science and Nutrition College of Community Science University of Agricultural Sciences,

Dharwad, Karnataka, India

Dr. Kavera Biradar

Professor, Department Genetics and Plant Breeding College of Agriculture, Hanumanamatti, University of Agricultural Sciences, Dharwad, Karnataka, India

Corresponding Author: Dileepa KC

M. Tech (Food Technology) Department of Food Processing Technology College of Community Science University of Agricultural Sciences, Dharwad, Karnataka, India

\section{Storage stability of groundnut products prepared from normal and high oleic acid varieties}

\author{
Dileepa KC, Hemalatha S, Pushpa Bharati and Kavera Biradar
}

DOI: https://doi.org/10.22271/chemi.2020.v8.i5g.10342

\begin{abstract}
Fatty acid composition of groundnut oil is an important trait from the point of human nutrition and oil stability during storage. In the present study the products of oleic acid rich groundnut variety, Dh-245 and normal groundnut variety, GPBD-4 were studied and compared for oxidative stability upon storage. The peanut butter, chikki and fried groundnuts were prepared and stored for three months at ambient temperature. The PV, FFA and fatty acid composition were analysed frequently. Results revealed that the PV and FFA increased during storage period. The PV of fried groundnuts of Dh-245 and GPBD-4 (15.58 and 21.23 meq $\mathrm{O}_{2} / \mathrm{kg}$ ) and that of chikki of GPBD-4 (19.69 meq $\mathrm{O}_{2} / \mathrm{kg}$ ) crossed unacceptable limit of 15 meqO$/ 2$ kg at the end of storage. The per cent decrease in the linoleic acid content was observed less in those products prepared from Dh-245 variety (11 to 14\%) compared to the products made from GPBD-4 variety ( 21 to $24 \%$ ). In other words it can be said that the products made from Dh 245 variety has good storage stability compared to GPBD 4 variety.
\end{abstract}

Keywords: Groundnut products, oleic acid, oxidative stability, fatty acid composition

\section{Introduction}

Groundnut also called peanut (Arachis hypogaea), belongs to legume family Fabaceae. Groundnut oilseed crop is part of the economy of many countries such as the United States, India, China, Russia and Mexico. India ranks second after China with a production of 8.32 million tonnes. More than 50 per cent of the groundnut produced is used for oil extraction. Rest are either consumed as kernels or processed into various products like peanut butter, milk, cheese analogs, beverages, plumpy nut (a ready to use therapeutic food) and chocolate additives. Groundnuts have good amount of proteins (25-28\%) and lipids (50-55\%). Oleic acid, a monounsaturated fatty acid, and linoleic acid, a polyunsaturated fatty acid, constitute approximately $80 \%$ of the total fatty acid composition of groundnut (Ahmed \& Young 1982) [1]. In addition, they are rich source of other nutrients such as fiber, niacin, folate, vitamin E, magnesium, manganese and phosphorous. Groundnuts also contain phytochemicals such as phytosterols and phenolic compounds (Higgs, 2003) ${ }^{[14]}$. The presences of these components contribute to healthy human diet in many countries.

Due to their high oil content, groundnuts are rich in energy but are susceptible to developing rancidity and off-flavors through lipid oxidation. The complex oxidative process has been found to be accelerated by the action of light and oxygen, additionally water activity and high temperatures have shown acceleration of oxidation alongside the presence of pro-oxidants such as metal ions (Buettner 1993; Blomhoff et al. 2006; Jensen et al. 2005; Mexis et al. 2009) $[8,6,16,19]$. Some of the products arising from oxidation such as free radicals or oxysterols have been described to have negative or even toxic health effect (Guillen and Goicoechea 2008) ${ }^{[12]}$. In addition, the oxidation of PUFA in food may be related to diseases such as atherosclerosis, diabetes, and cancer (Grossi M et al 2015).

Differences in the fatty acid composition have been attributed to several factors, including genotype, the level of maturity of the seed, season, year and geographical area of production (Brown et al 1975) ${ }^{[7]}$. Recently, several attempts have been made to produce new cultivars with improved nutritional qualities such as chemical composition, phytochemicals and high oleic/linoleic ratio (Jonnala et al., 2005) ${ }^{[17]}$. Oils with high content of monounsaturated fatty acid (oleic acid) are less susceptible to oxidative changes during refining and storage. life and thus improve the oxidative stability of peanut products (Isleib et al., 2006) ${ }^{[15]}$. 
Linoleic acid has two double bonds and is more susceptible to oxidative rancidity than oleic acid and the saturated fatty acids (Kratz et al. 2002) ${ }^{[18]}$.

Studies have reported that consumption groundnuts associated with a reduced risk of cardiovascular disease without leading to significant weight gain (Rajaram \& Sabaté, 2008) ${ }^{[22]}$.

The oxidation of fat and fat containing foods is responsible for the deterioration in the food quality and nutritive value. They may change nutritional value of food because of impact on essential fatty acids, proteins and vitamins (Chun et al. 2005, Hęś and Korczak 2007) ${ }^{[11,13]}$.

The University of Agricultural Sciences, Dharwad has developed new groundnut variety called $\mathrm{Dh} 245$, which is rich in oleic acid content compared to other groundnut varieties. The effect of storage on the oxidative stability of products made from groundnuts with different oleic acid content is the major interest to and the nutritional benefits.

Hence the present study focused on the effect of storage on the oxidative stability of the products made from groundnuts with different oleic acid content to improve the keeping quality and to harness its health benefits.

\section{Materials and Methods \\ Experimental materials}

Experimental materials for the present research work comprised of high oleic acid groundnut variety (Dh 245) and normal oleic acid groundnut variety (GPBD 4) which were procured from All India Coordinated Research Project (AICRP) on oilseeds, UAS Dharwad. The groundnuts procured were harvested during 2017-18.

The groundnut shells were removed using manual groundnut decorticator and oil was extracted from selected varieties using table top hot oil expeller.

\section{Preparation of groundnut products}

The groundnut products like peanut butter (PB) and groundnut chikki $(\mathrm{CH})$ of both varieties were prepared using standard recipe and fried groundnuts (FG) prepared by deep fat frying of groundnuts.

Preparation of peanut butter: Groundnuts $300 \mathrm{~g}$, Salt $4.8 \mathrm{~g}$, Garlic $4.8 \mathrm{~g}$, Jeera $3 \mathrm{~g}$, Oil $6.6 \mathrm{ml}$, Chili powder $0.2 \mathrm{~g}$, Jaggery $6.6 \mathrm{~g}$ were taken. Groundnuts were roasted at $140{ }^{\circ} \mathrm{C}$ for 10 min and outer skin was removed. Jaggery was grated using manual grater. All the ingredients were weighed and mixed. Then that mixture was grinded until it becomes fine paste.

Preparation of groundnut chikki: Groundnuts 500g, Jiggery $450 \mathrm{~g}$, Liquid glucose $25 \mathrm{~g}$, Water $100 \mathrm{ml}$, Hydrogenated fat $1 / 4$ t. sp were taken. Groundnuts were roasted at $140^{\circ} \mathrm{C}$ for $10 \mathrm{~min}$ and outer skin was removed. Jaggery was melted in a bowl by adding water, liquid glucose and hydrogenated fat to prepare syrup.

To test the syrup was prepared or not, one drop of syrup was poured in cold water. If the syrup becomes hard immediately the syrup is ready.

Then roasted groundnuts were added and mixed thoroughly. Chikki mould or a tray was besmeared with small quantity of hydrogenated fat. Then the mixture of syrup and groundnuts was poured into the tray and pressed. Then the mixture was cut into small square shape with the knife.

Preparation of fried groundnuts: Deep fat frying was done for groundnuts at $160{ }^{\circ} \mathrm{C}$ for 2 min using frying pan and the oil of same variety. The temperature was maintained using Infra red (IR) thermometer.

\section{Storage study of groundnut products}

The products were stored for three months at ambient condition in HDPE packaging material. The FFA \& PV of the samples was analysed once in a week and fatty acid profile was analysed once in a month.

\section{Extraction of oil from samples for analysis}

Oils from groundnut products were extracted using solvent extraction method using $\mathrm{n}$-hexane as a solvent. The products were crushed and poured to conical flask containing equal amount of n-hexane and kept overnight in rotary shaker, so oil gets leached into solvent. Then the mixture was centrifuged to separate solvent from solid matter. The supernatant was collected and subjected to vacuum rotary evaporator to remove solvent from oil. Then the oil was kept in oven for some time to evaporate remaining $\mathrm{n}$-hexane residue.

\section{Analysis of samples for oxidative stability}

Fatty acid composition analysis

Preparation of FAME: The fatty acid methyl esters (FAME) of the samples were prepared for analysis as per the Palm Oil Research Institute of Malaysia (Anon, 1995) ${ }^{[3]}$ method

Analysis of FAME by GC-FID: The fatty acid composition analysis was performed with an Agilent gas chromatograph (GC) equipped with a flame ionization detector (FID). The fatty acid compositions were used calculate oleic acid to linoleic acid ratio $(\mathrm{O} / \mathrm{L})$, unsaturation to saturation ratio $(\mathrm{U} / \mathrm{S})$ and $\%$ saturation by following formulae.

$\mathrm{O} / \mathrm{L}=$ oleic acid content/linoleic acid content,

$\mathrm{U} / \mathrm{S}=$ sum of unsaturated fatty acids/sum of saturated fatty acids,

$\%$ saturation $=$ sum of saturated fatty acids/number of saturated fatty acids

\section{Percentage free fatty acid (FFA)}

Percentage free fatty acid was determined using the recommended method of the American Oil Chemists' Society (Anon, 1993) ${ }^{[2]}$.

\section{Peroxide Value (PV)}

The peroxide value of the oil samples was determined using the standard American Oil Chemists' Society (Anon, 1998) ${ }^{[4]}$ method. The method is based on the iodometric titration that quantifies the iodine produced from potassium iodide by the peroxides present in the oil.

\section{Statistical analysis}

The observations recorded in respect of all the above parameters are represented as the means and standard deviations for the replicates. Two way and three way ANOVA was carried out by SPSS software (version 23). Significant difference within the group was defined at $\mathrm{p}<0.05$ using Duncan's multiple range test.

\section{Results and Discussion}

Effect of storage of groundnut products on peroxide value and free fatty acids

The peroxide value of groundnut products during storage is shown in the figure 1 . The peroxide value of peanut butter, groundnut chikki and fried groundnut s of both $\mathrm{Dh} 245$ and GPBD 4 varieties increased significantly during storage. In case of Dh 245 groundnut variety the peroxide value in the peanut butter, chikki and fried groundnuts increased from 2.54 to $8.58 \mathrm{meqO}_{2} / \mathrm{kg}, 6.25$ to $12.82 \mathrm{meqO}_{2} / \mathrm{kg}$ and 5.73 to $15.58 \mathrm{meqO}_{2} / \mathrm{kg}$, and the per cent increase was $320.5,204.97$ and 271.75 respectively. Whereas, in GPBD 4variety the peroxide value increased from 3.39 to $14.22 \mathrm{meqO}_{2} / \mathrm{kg}, 9.23$ 
to $19.69 \mathrm{meqO}_{2} / \mathrm{kg}$ and 7.53 to $21.23 \mathrm{meqO}_{2} / \mathrm{kg}$ respectively, and the per cent increase was 419.6, 213.47 and 281.75 respectively.

The changes in percent free fatty acids of groundnut products during storage are given in the Figure 2. The free fatty acids increased in all the products of both GPBD 4 and Dh 245 varieties during storage period of 180 days. In Dh 245 variety the free fatty acid content increased from 0.27 to 0.67 per cent, 0.29 to 0.42 per cent and 0.29 to 0.45 per cent in peanut butter, chikki and fried groundnuts respectively. The per cent increase observed was 252.8, 145.89 and 155.47 respectively. Whereas in case of GPBD 4 variety the free fatty acid content increased from 0.35 to 0.92 per cent, 0.34 to 0.59 per cent and 0.29 to 0.55 per cent in peanut butter, chikki and fried groundnut respectively and the per cent increase observed was 263.24, 171.8 and 185.81 respectively.

The PV and FFA increased during storage period. This may due to the chain reaction of oxidation process that was initiated during thermal processing and/or oxygen present inside the packaging material and/or transpiration of oxygen into packaging material from outside (Smouse 1994; Jelen et al., 2000). The oxidation rate in thermal oxidation is faster than auto-oxidation and hydroperoxides, the primary oxidation products are decomposed rapidly and produces secondary oxidation products such as aldehydes and ketones (Choe and Min, 2007) ${ }^{[10]}$. The results are in accordance with the reports of Chetana et al., (2011) [9] and Rosalli et al., (2015) ${ }^{[23]}$ for chikki and peanut butter respectively. At the initial stage of storage the PV was found higher in chikki followed by fried groundnuts and peanut butter, but at the end of storage period the highest PV was observed in fried groundnuts followed by chikki and peanut butter. In the study conducted by Muttagi et al, (2014) ${ }^{[20]}$ the PV was found higher in oilseed paste than chikki throughout the storage period but in the current study the PV of peanut butter was lower than chikki. This may be due to the ingredients we have used i.e. turmeric powder and garlic as they have good anti oxidant properties (Banerjee et al., 2013 and Nurwantoro et al., 2015) ${ }^{[5,21]}$

Between the varieties, the products made from Dh 245 variety gave lower PV than the products made from GPBD 4. This result is comparable to the study conducted by Muttagi et al., $2014^{[20]}$. Where the products made from groundnuts gave lower peroxide values than products made from sunflower kernels as sunflowers have more unsaturated fats than groundnuts.

The FFA of peanut butter increased rapidly during storage followed by fried groundnuts and chikki.

FFA was higher in peanut butter compared to other products at the end of storage. Within the products the FFA increased rapidly in the variety GPBD 4 than the products made from the variety $\mathrm{Dh} 245$. The PV and FFA of peanut butter increased rapidly compared to chikki and fried groundnuts, this may due to separation of oil from the peanut butter (Rosalli et al., 2015) ${ }^{[23]}$.

\section{Changes in the fatty acid composition of groundnut products during storage}

The fatty acid composition of groundnut products during storage period of three months was showed in table 1 .

Table 1: Fatty acid composition of groundnut products during storage

\begin{tabular}{|c|c|c|c|c|c|c|c|c|c|c|c|}
\hline \multirow{2}{*}{ Storage (Months) } & \multicolumn{8}{|c|}{ Fatty acid composition } & \multirow{2}{*}{$\mathrm{O} / \mathrm{L}$} & \multirow{2}{*}{$\mathbf{U} / \mathbf{S}$} & \multirow{2}{*}{$\%$ Saturation } \\
\hline & C16:0 & C18:0 & C18:1 n9 & C18:2 n6 & C20:0 & C20:1 n9 & C22:0 & C24:0 & & & \\
\hline \multicolumn{12}{|c|}{ Peanut butter of GPBD 4 variety } \\
\hline 0 & 8.45 & 3.35 & 50.20 & 22.68 & 2.65 & 3.96 & 5.33 & 2.59 & 2.21 & 3.43 & 22.4 \\
\hline 1 & 9.64 & 3.06 & 49.54 & 22.14 & 2.54 & 2.12 & 6.55 & 3.98 & 2.24 & 2.86 & 25.77 \\
\hline 2 & 10.98 & 3.28 & 47.84 & 19.50 & 4.38 & 2.03 & 7.64 & 3.77 & 2.45 & 2.31 & 30.1 \\
\hline 3 & 10.82 & 4.9 & 46.33 & 18.09 & 4.65 & 1.35 & 8.84 & 4.88 & 2.56 & 1.93 & 34.09 \\
\hline$\%$ change & & & & $21 \%$ & & & & & $16 \%$ & $44 \%$ & $52 \%$ \\
\hline \multicolumn{12}{|c|}{ Peanut butter of Dh 245 variety } \\
\hline 0 & 8.95 & 2.91 & 56.18 & 20.94 & 1.84 & 2.55 & 4.06 & 2.42 & 2.68 & 3.95 & 20.18 \\
\hline 1 & 9.65 & 3.65 & 54.38 & 20.16 & 2.41 & 2.19 & 4.98 & 2.15 & 2.70 & 3.36 & 22.84 \\
\hline 2 & 10.19 & 3.32 & 53.28 & 19.65 & 2.59 & 2.19 & 5.52 & 3.11 & 2.71 & 3.04 & 24.7 \\
\hline 3 & 11.08 & 3.26 & 52.58 & 18.64 & 2.67 & 2.53 & 6.04 & 3.14 & 2.82 & 2.82 & 26.19 \\
\hline$\%$ change & & & & $11 \%$ & & & & & $5 \%$ & $29 \%$ & $30 \%$ \\
\hline \multicolumn{12}{|c|}{ Chikki of GPBD 4 variety } \\
\hline 0 & 9.98 & 3.16 & 50.89 & 24.19 & 1.86 & 1.76 & 4.84 & 2.32 & 2.10 & 3.47 & $22.2 \%$ \\
\hline 1 & 10.05 & 3.59 & 49.45 & 22.65 & 2.55 & 1.26 & 5.53 & 3.54 & 2.18 & 2.90 & 25.26 \\
\hline 2 & 10.38 & 3.55 & 48.86 & 21.95 & 2.76 & 2.17 & 6.09 & 3.95 & 2.23 & 2.73 & $26.7 \%$ \\
\hline 3 & 11.99 & 3.85 & 45.98 & 18.56 & 4.56 & 2.14 & 7.94 & 4.64 & 2.48 & 2.02 & 32.98 \\
\hline$\%$ change & & & & $24 \%$ & & & & & $18 \%$ & $42 \%$ & $49 \%$ \\
\hline \multicolumn{12}{|c|}{ Chikki of Dh 245 variety } \\
\hline 0 & 9.40 & 2.81 & 55.54 & 21.19 & 1.72 & 2.45 & 4.20 & 2.59 & 2.62 & 3.82 & $20.7 \%$ \\
\hline 1 & 10.35 & 3.25 & 53.54 & 20.51 & 1.65 & 2.06 & 4.92 & 3.38 & 2.61 & 3.23 & 23.55 \\
\hline 2 & 10.63 & 3.53 & 51.95 & 19.67 & 2.64 & 1.52 & 6.84 & 3.04 & 2.64 & 2.74 & $26.7 \%$ \\
\hline 3 & 11.25 & 3.84 & 50.92 & 18.90 & 2.14 & 1.42 & 7 & 5 & 2.82 & 2.41 & 29.23 \\
\hline$\%$ change & & & & $11 \%$ & & & & & $3 \%$ & $36 \%$ & $41 \%$ \\
\hline \multicolumn{12}{|c|}{ Fried groundnuts of GPBD 4 variety } \\
\hline 0 & 10.52 & 3.13 & 51.61 & 25.09 & 1.78 & 1.84 & 4.33 & 1.71 & 2.06 & 3.66 & $21.5 \%$ \\
\hline 1 & 11.27 & 3.63 & 50.84 & 23.64 & 2.15 & 1.27 & 5.05 & 1.86 & 2.15 & 3.16 & 23.96 \\
\hline 2 & 12.74 & 5.68 & 47.88 & 20.24 & 3.69 & 1.73 & 5.94 & 1.69 & 2.37 & 2.35 & $29.7 \%$ \\
\hline 3 & 13.12 & 4.96 & 45.59 & 19.15 & 5.05 & 2.47 & 6.65 & 2.59 & 2.38 & 2.08 & 32.37 \\
\hline$\%$ change & & & & $24 \%$ & & & & & $16 \%$ & $43 \%$ & $51 \%$ \\
\hline \multicolumn{12}{|c|}{ Fried groundnuts of Dh 245 variety } \\
\hline 0 & 9.98 & 2.85 & 54.12 & 21.50 & 2.80 & 2.62 & 3.27 & 1.82 & 2.43 & 3.78 & $20.7 \%$ \\
\hline 1 & 10.82 & 3.58 & 53.31 & 21.74 & 2.15 & 2.01 & 4.04 & 2.21 & 2.45 & 3.38 & 22.8 \\
\hline 2 & 11.65 & 3.02 & 52.01 & 20.58 & 1.99 & 2.63 & 5.36 & 2.44 & 2.53 & 3.08 & $24.5 \%$ \\
\hline 3 & 12.58 & 3.95 & 50.83 & 18.91 & 2.23 & 1.67 & 6.18 & 3.61 & 2.69 & 2.50 & 28.55 \\
\hline$\%$ change & & & & $14 \%$ & & & & & $7 \%$ & $34 \%$ & $38 \%$ \\
\hline
\end{tabular}


The samples were calculated for oleic to linoleic ratio $(\mathrm{O} / \mathrm{L})$, unsaturated to saturated fatty acids ratio (U/S) and percentage saturation (\% saturation). Where the saturated fatty acids (C16:0, C18:0, C20:0, C22:0 \& C24:0) and oleic to linoleic acid ratio $(\mathrm{O} / \mathrm{L})$ increased whereas unsaturated fatty acids (C18:1, C18:2 \& C20:1) decreased in the composition during storage. In Dh 245 variety the linoleic acid decreased from 20.94 to 18.64 per cent, 21.19 to 18.90 per cent and 21.50 to 18.91 per cent in peanut butter, chikki and fried groundnuts respectively with the per cent decrease of 11,11 and 14 . In GPBD 4 variety, the linoleic acid decreased from 22.68 to 18.09 per cent, 24.19 to 18.56 per cent and 25.09 to 19.15 per cent with the per cent decrease of 21,24 and 24 in peanut butter, chikki and fried groundnuts respectively. In Dh 245 variety the U/S radio decreased by 29, 36 and 34 per cent in peanut butter, chikki and fried groundnuts respectively and in case of GPBD 4 variety it was 44,42 and 43 per cent respectively. The per cent increase in $\mathrm{O} / \mathrm{L}$ ratio of peanut butter, chikki and fried groundnuts was 5, 3 and 7 per cent in Dh 245 variety, respectively and 16, 18 and 16 per cent in
GPBD 4 variety, respectively. In peanut butter, chikki and fried groundnuts per cent increase in the \% saturation observed was 30, 41 and 38 in respectively in Dh 245 variety. Whereas 52, 49 and 51 per cent respectively in GPBD 4 variety. In the products made from GPBD 4 variety, the per cent increase in $\mathrm{O} / \mathrm{L}$ ratio ranged from 16 to 18 (figure 15), the per cent increase in the \% saturation was 49 to 54 and the per cent decrease in the linoleic acid content ranged from 21 to 24. Where as in case of products made from $\mathrm{Dh} 245$ variety, the per cent increase in $\mathrm{O} / \mathrm{L}$ ratio ranged from 3 to 7 , the per cent increase in the \% saturation was 30 to 41 and the per cent decrease in the linoleic acid content ranged from 11 to 14 . The per cent decrease in linoleic acid content observed was more in case of fried groundnuts of both varieties. So the fatty acid composition altered to a greater extent in GPBD 4 groundnut variety than $\mathrm{Dh} 245$ groundnut variety. This indicated that the variety Dh 245 was more stable towards the alteration in the fatty acid composition during the combination of both processing and storage.

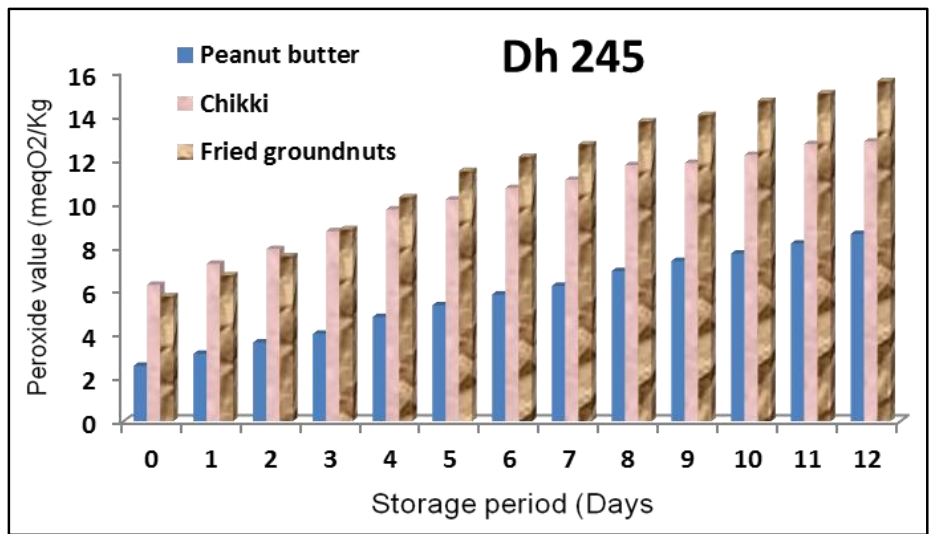

A) Peroxide value of products made from $\mathrm{Dh} 245$ groundnut variety during storage

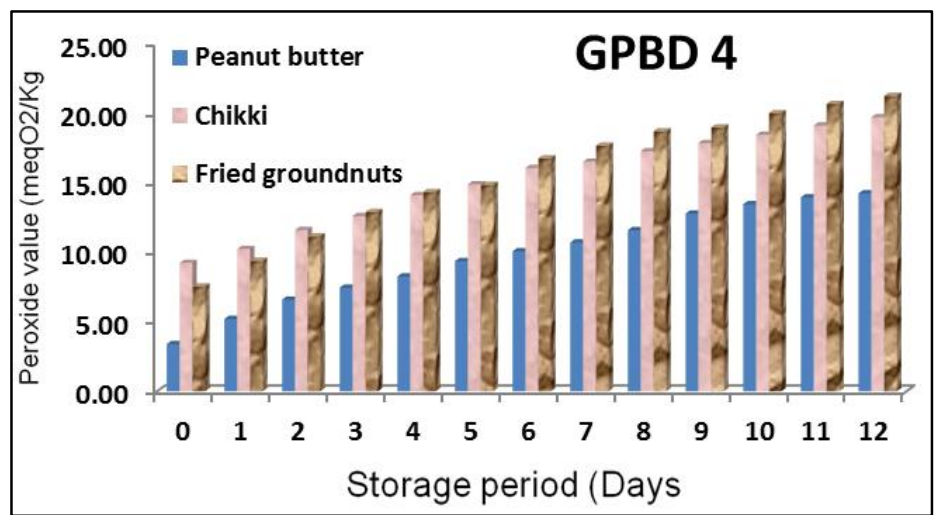

B) Peroxide value of products made from GPBD 4 groundnut variety during storage

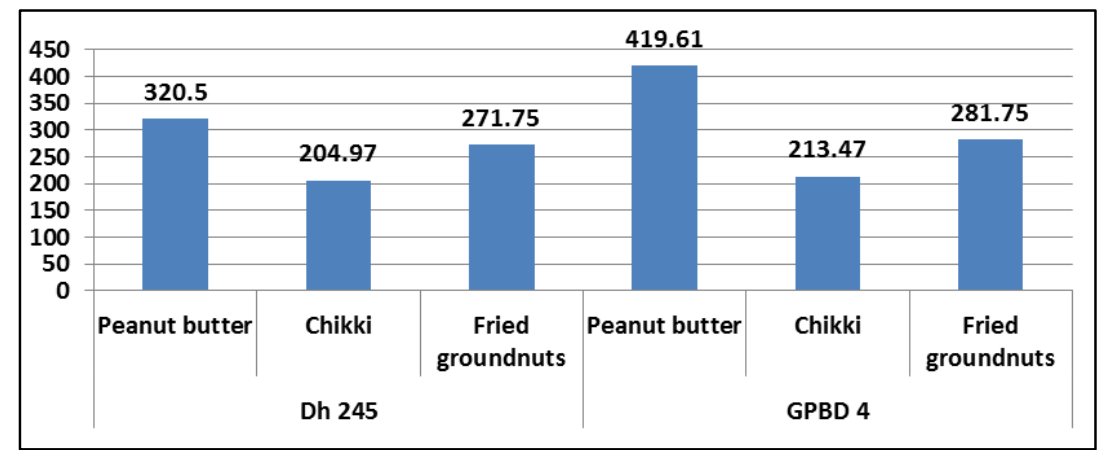

C) Per cent increase in peroxide value of groundnut products made from Dh245 and GPBD 4 variety during storage

Fig 1: Peroxide value of groundnut products during storage 


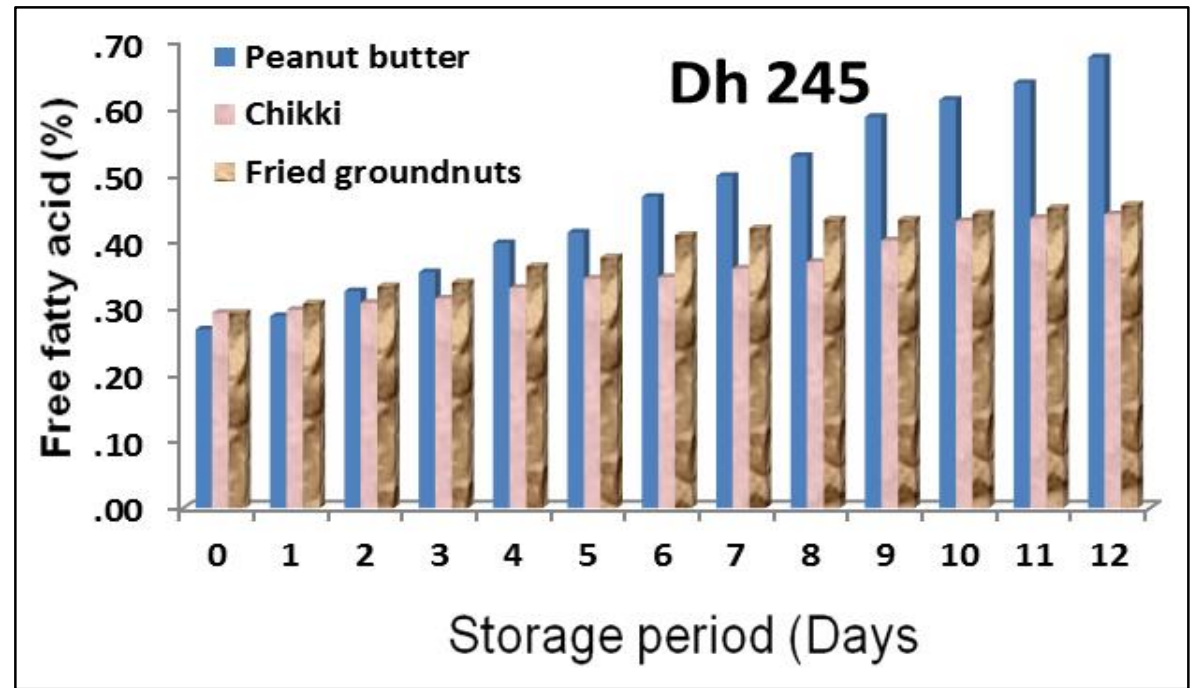

A) Free fatty acid content of products made from $\mathrm{Dh} 245$ groundnut variety during storage

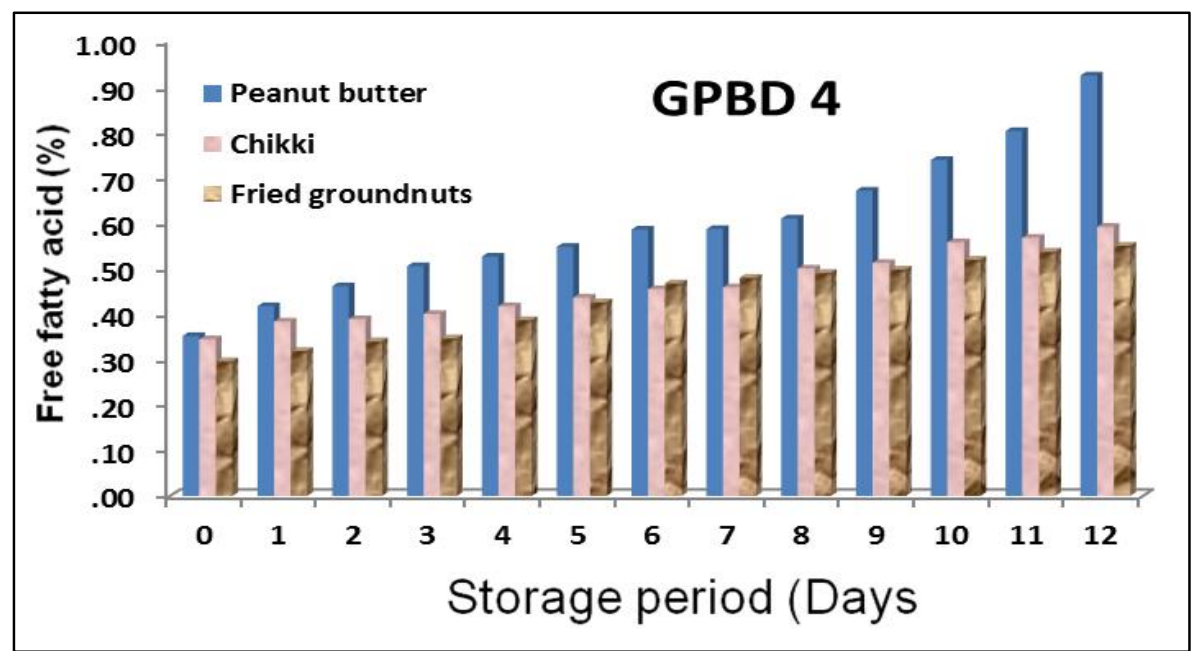

B) Free fatty acid content of products made from GPBD 4 groundnut variety during storage

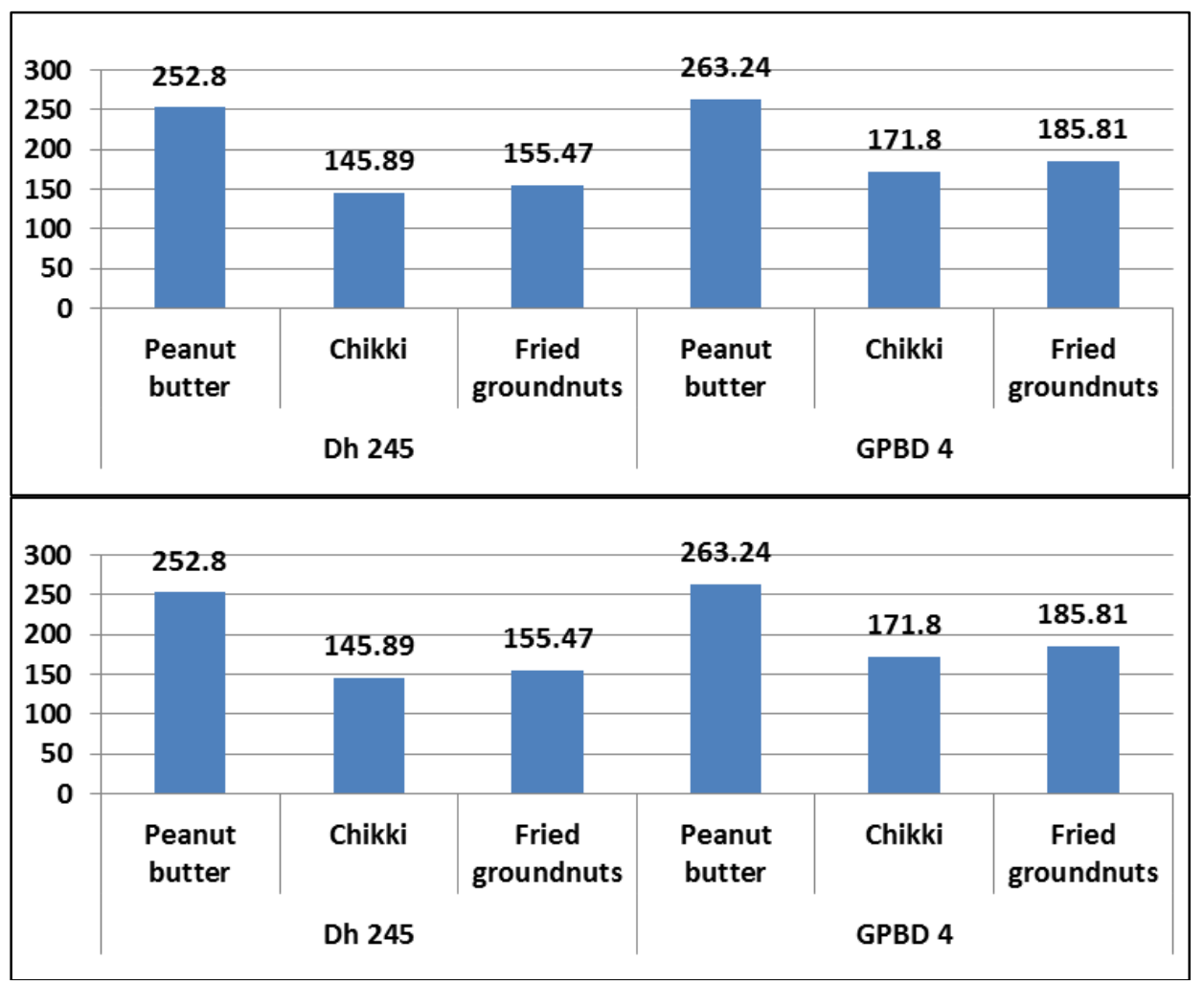

C) Per cent increase in free fatty acid of groundnut products made from Dh245 and GPBD 4 variety during storage 
Fig 2: Free fatty acid content of groundnut products during storage

\section{Conclusion}

From this study it can be concluded that the products made from oleic acid rich groundnut variety $\mathrm{Dh} 245$ has good oxidative stability than conventional GPBD 4 variety during storage. Peanut butter has good oxidative stability among products if oil is not separated. So in commercial point of view oleic acid rich groundnut can be used for products to increase their shelf life and to improve oxidative quality. Future studies has to be done to investigate oxidative stability of products of oleic rich groundnuts with the combination of antioxidant activity and moisture content, humidity, temperature etc. to output the effectiveness of this groundnut variety towards oxidative stability.

\section{References}

1. Ahmed EM, Young CT. Composition, quality and flavour of peanuts. In Peanut Science and Technology, ed. by H.E. Pattee and. C.T. Young. Amer. Peanut Res. Edu. Soc. Yoakum, Texas, 1982, 655-688.

2. Anonymous. Official methods and recommended practices of the American Oil Chemist's Society. AOCS Press, Washington, DC, 1993.

3. Anonymous. PORIM Test Methods. Palm Oil Research Institute of Malaysia, Ministry of Primary Industries Malaysia, 1995.

4. Anonymous. American Oil Chemist's Society official method Cd 8b-90, AOAC Press: Champaign, IL, 1998.

5. Banerjee A, Ghosh S, Ghosh M. Anti-oxidative effect of turmeric on frying characteristics of soybean oil. J. Food Sci. Technol. 2015; 52(3):1760-1765.

6. Blomhoff R, Carlsen MH. Andersen LF and Jacobs DR. Health benefits of nuts: potential role of antioxidants. British J of Nutri. 2006; 96(2):52-S60.

7. Brown DF, Cater CM. Mattil KF and Darroch JG. Effect of variety, growing location and their interaction on the fatty acid composition of peanuts. J Food Sci. 1975; 40:1055-1060.

8. Buettner GR. The pecking order of free radicals and antioxidants: lipid peroxidation, [alpha]-tocopherol, and ascorbate. Archives of Biochemistry and Biophysics. 1993; 300(2):535-543.

9. Chetana R, Sunkireddy YR. Preparation and quality evaluation of peanut chikkiincorporated with flaxseeds. J. Food Sci. Technol. 2011; 48(6):745-749.

10. Choe E, Min DB. Chemistry of deep-fat frying oils. J. Food Sci. 2007; 72(5):77-86.

11. Chun J, Lee J, Eitenmiller RR. Vitamin E and oxidative stability during storage of raw and dry roasted peanuts packaged under air and vacuum. J Food Sci. 2005; 70:292-297.

12. Guillen MD, Goicoechea E. Formation of oxygenated a,b-unsaturated aldehydes and other toxic compounds in sunflower oil oxidation at room temperature in closed receptacles. Food Chem. 2008; 111:157-164.

13. Hęś M, Korczak J. Wpływ produktów utleniania lipidów na wartość odżywczą białka. Nauka Przyr. Technol. 2007; 1:1-15.

14. Higgs J. The beneficial role of peanuts in the diet - Part 2. Nutrition and Food Sci. 2003; 33(2):56-64.

15. Isleib T, Patte H, Sanders T. Hendrix K. and Dean L. Compositional and Sensory Comparisons between Normal- and High oleic peanuts. J Agric. Food Chem. 2006; 54:173-179.
16. Jensen PN. Danielsen B. Bertelsen G. Skibsted LH. and Andersen ML. Storage stabilities of pork scratchings, peanuts, oatmeal and muesli: comparison of ESR spectroscopy, headspace-GC and sensory evaluation for detection of oxidation in dry foods. Food Chem. 2005; 91(1):25-38.

17. Jonnala RS, Dunford NT, Chenault K. Nutritional composition of genetically modified peanut varieties. J. Food Sci. 2005; 70:254-256.

18. Kratz M, Cullen P, Kannenberg F, Kassner A, Fobker M, Abuja PM et al. Effects of dietary fatty acids on the composition and oxidizability of low-density lipoprotein. European J. Clin. Nutr. 2002. 56(1): 72-81

19. Mexis SF, Badeka AV, Riganakos KA, Karakostas KX, Kontominas MG. Effect of packaging and storage conditions on quality of shelled walnuts. Food Control. 2009; 20(8):743-751.

20. Muttagi GC, Joshi N, Shadakshari YG, Chandru R. Storage stability of value added products from sunflower kernels. J Food Sci. Technol. 2014; 51(9):1806-1816.

21. Nurwantoroa, Bintoroa VP, Legowoa AM, Purnomoadib A, Setiania BE. Garlic Antioxidant (Allium sativum L.) to Prevent Meat Rancidity. Procedia Food Science. 2015; 3:137-141.

22. Rajaram S, Sabaté J. Nuts, body weight and insulin resistance. British J Nutri. 2006; 55:S79-S86

23. Rozalli MNH, Chin NL, Yusof YA, Mahyudin N. Quality changes of stabilizer-free natural peanutbutter during storage. J Food Sci. Technol. 2015; 54:25-26. 